\title{
Simposio caleidoscópico: una mirada poliédrica hacia los cuerpos bellos del Banquete de Platón
}

\author{
Il Banchetto di Platone | Marco Ferreri| 1989
}

\author{
Abril Sofía Sain* \\ Facultad de Filosofía y Letras - Universidad de Buenos Aires
}

Recibido 20 de septiembre de 2021; aprobado 15 de octubre de 2021

\begin{abstract}
Resumen
Focalizaremos este trabajo en el tratamiento platónico del cuerpo en el Banquete, bajo un abordaje particular: el de considerar la dinámica dialógica de este texto al modo de un "caleidoscopio" a través del cual Platón nos presenta imágenes, las elabora, complejiza y transforma. Atenderemos en particular los primeros cuatro discursos, mostrando que ya desde el comienzo hay en el diálogo una construcción conceptual fuerte y una visión positiva del cuerpo, antes del elogio de Sócrates. Tras esta experiencia óptica a través de los elogios de Fedro, Pausanias, Erixímaco y Aristófanes analizaremos la vinculación entre la esfera de la corporalidad y (1) el deseo sexual, (2) la ética y (3) la felicidad. Concluiremos que en este diálogo Platón elabora un modelo antropológico en el cual el rol del cuerpo se hace indudablemente presente para la búsqueda filosófica. Finalmente, tejeremos un contrapunto con el film Il Banchetto di Platone de Marco Ferreri (1989), el cual relata el encuentro en la casa de Agatón siguiendo el texto platónico casi al pie de la letra. Contrapondremos nuestra tesis con ciertas decisiones escénicas del film, según las cuales el cuerpo queda devaluado a la esfera más oscura de lo puramente sexual desligado del carácter filosófico. A la luz de este contrapunto, regresaremos, no obstante, al film, ya que allí lo corporal se impone como un claro protagonista y, aunque apegado a la hermenéutica tradicional del diálogo, abre igualmente la posibilidad de una reflexión crítica sobre el rol que puede tener el cuerpo en la acción filosófica.
\end{abstract}

Palabras clave: Platón | Banquete | cuerpo | deseo sexual | ética | felicidad

Kaleidoscopic Symposium: a multifaceted look at the beautiful bodies from Plato's Banquet

\begin{abstract}
We will focus this work on the Platonic treatment of the body at the Symposium, under a particular approach: to consider the dialogic dynamics of this text in the manner of a "kaleidoscope" through which Plato presents us with images, elaborates them, complicates them and transforms them. We will attend in particular to the first four speeches, showing that already from the beginning there is in the dialogue a strong conceptual construction and a positive vision of the body, before the praise of Socrates. After this optical experience through the praise of Phaedrus, Pausanias, Eriximachus and Aristophanes, we will analyze the link between the sphere of corporeality and (1) sexual desire, (2) ethics and (3) happiness. We will conclude that in this dialogue Plato elaborates an anthropological model in which the role of the body is undoubtedly present for the philosophical search. Finally, we will weave a counterpoint with the film Il Banchetto di Platone by Marco Ferreri (1989), which recounts the meeting in the house of Agaton following the Platonic text almost to the letter. We will contrast our thesis with certain scenic decisions of the film, according to which the body is devalued to the darkest sphere of the purely sexual detached from the philosophical character. In the light of this counterpoint, we will return to the film, since there the corporeal is imposed as a clear protagonist and, although attached to the traditional hermeneutics of dialogue, it also opens the possibility of a critical reflection on the role that the body can have in philosophical action.
\end{abstract}

Keywords: Plato | Symposium | body | sexual desire | ethics | happiness

\section{Introducción}

No es muy profusa la literatura acerca de Platón que ofrece una interpretación positiva para el uso del cuerpo en la filosofía ${ }^{1}$. En general, en cambio, la línea interpretativa tradicional de la filosofía platónica pondera el papel del cuerpo como un impedimento para que el alma se dedique plenamente a la búsqueda de la sabiduría ${ }^{2}$.
En particular, el Banquete es leído como un simposio intelectual en el que el pensamiento de Platón es volcado únicamente en el discurso de Sócrates y Diotima, allí donde la iniciación erótica enseña - a partir de esta lectura - a rechazar todo obstáculo sensible en pos de encaminarse a la contemplación de la Belleza en sí. Pero ¿no leemos de la sabia sacerdotisa en el discurso del filósofo que "el que avanza adecuadamente tiene que co-

*abrilsain@gmail.com 
menzar en este asunto [amoroso] cuando es joven a ir hacia los cuerpos bellos". El hecho de que el camino filosófico comience dirigiéndose hacia los cuerpos bellos supone que es la naturaleza sensible del objeto la que es capaz de suscitar el interés por lo bello en sí. Dicho en otras palabras: es la belleza del cuerpo la que tiene la capacidad de provocar el movimiento inicial fundamental para que el proceso comience. En este trabajo me interesa atender al tratamiento platónico del cuerpo, que es tantas veces olvidado en el brío del ascenso. Pero además, quisiera poner el foco en las palabras que igualmente son, con frecuencia, desdeñadas: las de los primeros discursos del banquete. Mi propósito aquí es opuesto al de Cornford (1974) cuando afirma que ha de "pasar de largo los primeros discursos que esbozan distintas sugerencias que son recogidas o criticadas en el discurso de Sócrates" (p. 133)4.

Me inspira en esta ocasión la figura que sugiere la autora Peixoto (2012) para abordar la lectura del Banquete, la cual encuentro muy acertada. Ella propone que este diálogo nos ofrece una experiencia óptica, a la manera de un caleidoscopio de imágenes que se van reorganizando gradualmente (p. 178). Vale la pena descubrir la etimología de la curiosa palabra "caleidoscopio". Esta se compone de tres términos griegos: kalós, bello; eidos, imagen; y scopéo, mirar. Refiere, pues, a la visión de imágenes bellas. Iluminada por esta sugerencia, me propongo aquí mostrar la relevancia del cuerpo en los primeros cuatro discursos del Banquete, antes de la intervención del filósofo. Será el cuerpo bello, pues, quien encienda de deseo al amante y lo guíe a la Idea de la belleza, atrayéndolo con sus más palmarias representaciones. Al igual que lo hace Cortázar en Raymela, Platón nos lleva de aquí para allá y de allá para acá una y otra vez. Y, en esta dinámica de vidriecillos de colores que se mueven transformándose, somos llamadas y llamados a unir todas las partes, dirigiendo nuestra mirada a lo que es siempre en sí, pero también volviendo nuestros ojos a la realidad que nos circunda, distinguiendo allí la huella del verdadero ser.

En lo que sigue procuraré mirar al cuerpo en el primer giro caleidoscópico, es decir, aquel primer entrelazamiento de dinámicas discursivas que Platón nos presenta a través de una instancia lúdico-competitiva en la que los primeros personajes elogiarán al dios $\mathrm{Amor}^{5}$. $\mathrm{Al}$ comienzo de cada discurso el orador actual señalará la falla del anterior con la intención de completar o corregir las faltas con su propio encomio, con lo cual Platón se sirve de la estrategia dramática competitiva para armonizar los discursos entrelazándolos como los colores de un caleidoscopio: presenta una imagen, la elabora, la complejiza y la transforma. Tras esta experiencia óptica descubriremos que la noción de cuerpo se encuentra cargada de sentido desde el principio del diálogo, y que ya desde entonces Platón va dibujando un cuerpo potencialmente productivo para la búsqueda filosófica.

Para terminar, haré un repaso del tratamiento del cuerpo en los discursos analizados según se muestra en la película Il Banchetto di Platone de Marco Ferreri (1989), con la intención de contrastar nuestra lectura con una interpretación proveniente de la atmósfera cinematográfica, la cual, por su propia naturaleza, le otorga ya necesariamente, a través de la puesta en escena, una especie de cuerpo al banquete. En la película notamos, ciertamente, la fuerte presencia de la corporalidad en la casa de Agatón: los invitados están recostados en sus asientos, comiendo y bebiendo vino; la flautista decora el ambiente con una suave música; cuando llega Sócrates, se abraza fuertemente con Agatón, quien le pide que se siente a su lado, ya que ahora que se han "tocado", la sabiduría podrá serle transmitida si se quedan cerca ${ }^{6}$. Sin embargo, este lazo entre el cuerpo y el saber es rápidamente quebrado, cuando, antes de comenzar la ronda de los elogios al Amor, echan fuera a los esclavos, a la flautista y al resto de las mujeres, y ya sin las distracciones sensibles de la comida, el vino, la música y los cuerpos femeninos, se disponen solamente los hombres a escuchar sus discursos (esto ocurre de manera similar en el Banquete de Platón). Los primeros 36 minutos del film narran los discursos que aquí trataremos, pero si bien la película sigue casi al pie de la letra los diálogos y discursos de los personajes, su decisión escénica, es decir, la manera en que los elogios son narrados en imágenes, con los personajes en acción, muestra una interpretación que creemos se aleja de nuestra lectura. Nos parece que el film, siguiendo las lecturas más clásicas del Banquete, opta por darle un lugar central al discurso del filósofo Sócrates y deja al cuerpo devaluado en la esfera de lo puramente sexual y desligado de la acción filosófica de creación de verdadera virtud y acercamiento a la felicidad. No obstante, debido a la muy cercana literalidad que tiene la película para con el texto platónico y la oportunidad que esta nos ofrece de un banquete audiovisual, en tal sentido, corpóreo, el contrapunto que aquí propongo recupera el film de Ferreri como un interesante lugar para reabrir una reflexión crítica acerca del rol que puede tener el cuerpo en la acción filosófica. 


\section{Fedro}

En el primer encomio, el Amor aparece como una fuerza primordial divina que inspira a los amantes y los mueve hacia la realización de acciones virtuosas. Cuando uno está enamorado, describe Fedro, por nada del mundo quisiera que su amado lo encontrara haciendo algo vergonzoso, y en cambio desearía siempre ser reconocido frente a acciones dignas:

Yo afirmo que un hombre que ama, si lo descubrieran haciendo algo vergonzoso o padeciéndolo por cobardía sin poder defenderse, no sufriría tanto si fuera visto por su padre, o sus compañeros o ningún otro como si fuera visto por su amado. (178c-e)

En este sentido, no habría un mayor bien para un amante que un amado, y viceversa, porque el Amor infunde aquello que hay que seguir para vivir bien. $\mathrm{Y}$ es precisamente el cuerpo del amado en este esquema el que sirve como testigo vigilante de las acciones del amante, pues es necesaria la presencia del otro - aunque sea su posibilidad - para velar por la dignidad o indignidad de las acciones e infundir la vergüenza o el deseo de reconocimiento.

A partir de este planteo, la valentía puja su virtuosidad entre la naturaleza y la erótica: el valiente será aún más valiente cuando esté enamorado, pues potenciará su braveza con la intención de no verse avergonzado ni indigno frente a su amado. Para Ludueña (2015), en cambio, "el amor tiene una acción inferior a la de la naturaleza, pues el valiente por naturaleza es siempre valiente, pero el valiente enamorado lo es solo bajo los ojos del amado" (p. 44). Contra este argumento podemos pensar que el amante siempre está bajo los ojos - aunque sea potenciales - del amado, desde el momento en que se enamora. Es así como Fedro concluye:

Entonces, si pudiera surgir una ciudad o un ejército de amantes y amados [...], si ese tipo de hombres lucharan juntos, vencerían, aunque fueran pocos, por así decir, a todos los hombres, porque un hombre enamorado visto por su amado abandonando la formación militar, o tirando las armas lo soportaría realmente mucho menos que si fuera visto por todo el resto, y preferiría muchas veces morir antes que eso. (178e-179a)

De esta forma, la fuerza amorosa mueve al cuerpo a acciones virtuosas, instalando un poder en la presencia corporal del otro (amado o amante), cuya potencial o actual visión funciona como guía para el accionar virtuoso del valiente enamorado. En estos términos, el discurso de Fedro propone al amor corporal como la fuer- za más simple que acerca los individuos a relacionarse. Rowe (1998, p. 137) considera de hecho que el discurso de Fedro tiene como pretensión subyacente justificar la concesión de favores sexuales al amante a través de las circunstancias correctas. Las primeras palabras sobre el Amor en el banquete refieren a lo sexual como un deseo que se activa primariamente ante la presencia de otro cuerpo. Es cierto que Fedro está considerando al Amor como un dios, pero la primera noción del éros que aparece en este discurso es la de una fuerza divina que invade al amante y lo inunda de deseo para acercarse a su amado, y en este sentido puede considerarse que se lo trata como el dios del deseo sexual: el cuerpo según el encomio de Fedro es un cuerpo susceptible, un cuerpo que tan pronto como se vea enredado por el Amor, sentirá el ardor que lo une a otro cuerpo y se verá igualmente cautivo a experimentar vergüenza u orgullo siempre que su enamorado lo encuentre actuando indigna o dignamente. Pero con esto último entrevemos ya que la corporalidad amorosa está fuertemente ligada a la ética, pues de esta unión se generará una guía hacia la virtud y la felicidad. Sin más, Fedro vincula directamente una correcta moralidad con la adquisición de la prosperidad asegurando que el Amor es el mejor de los dioses en la posesión de la virtud y la felicidad: "Así sostengo yo que el Amor es el más antiguo, honorable y respetable de todos los dioses en la posesión de virtud y felicidad para los hombres tanto mientras viven como cuando han muerto" (180b).

\section{Pausanias}

En el segundo elogio la relevancia del cuerpo surge con su explicación de la genealogía del Amor. El Amor para Pausanias no es uno, como en el discurso de Fedro, sino doble, puesto que siempre está acompañado por la diosa Afrodita, que también es dos: una es la Afrodita Celestial, sin madre e hija del Cielo, quien acompaña al Amor Celestial; otra, la Afrodita Vulgar, hija de Zeus y Dione, que anda junto con el Amor Vulgar. Mientras que en el caso de Fedro el Amor carecía de padre y madre y había surgido al unísono con la Tierra (178b), el discurso de Pausanias acerca el Amor al reino humano al ponerle como compañera a Afrodita dotada de progenitores, sin por ello resultar menos divino. Platón va produciendo el efecto caleidoscópico cuidadosamente: primero, el Amor es uno y no tiene padre ni madre; luego, el Amor es doble: el que acompaña a la Afrodita Celestial no tiene madre pero sí padre, el Cielo (este Amor surge entonces 
solo de lo masculino); y el que acompaña a la Afrodita Vulgar tiene además de padre, madre (Zeus, dios masculino, y Dione, divinidad femenina). Con esto, Platón introduce la idea de procreación que tendrá esencial relevancia más adelante, ya que la actividad erótica será descripta como la procreación en lo bello, y de esto se tratará igualmente la actividad filosófica.

Así pues, mientras que el cuerpo en el caso de Fedro tenía que ver exclusivamente con el del ser humano y el Amor solo inspiraba en los individuos una fuerza que guiaba un camino virtuoso, la corporalidad en el caso de Pausanias se verá implicada desde la propia estirpe del dios, según participe en su origen solo de lo masculino, o de lo femenino y lo masculino. Si bien esto no le otorga un cuerpo físico real al dios, no debemos olvidar que los griegos de la Antigüedad solían caracterizar a los dioses de manera antropomórfica, con lo cual los acercaban al Más Acá, entre los problemas y las acciones de los seres humanos en la tierra. La idea de la corporalidad de los dioses permite establecer un sistema simbólico para pensar la relación entre los seres humanos y los seres divinos. Según lo piensa Vernant (2001), este código corporal instaura una especie de "subcuerpo" destinado al ser humano que define su carácter distintivo de mortalidad, limitación y deficiencia en relación con la idea de un cuerpo mayor que está supuesto como contracara de aquel, un "supercuerpo", es decir, el cuerpo inmortal de los dioses. El cuerpo humano en este sentido encuentra otro lugar desde el cual definirse, a través de un análisis por contraste, en comparación con el cuerpo divino. Entonces se puede explicar la necesidad humana del crecimiento, el desarrollo, y también el declive, el debilitamiento, y la muerte.

Por otro lado, la inclusión prácticamente inevitable de Afrodita es también la ineludible inclusión del cuerpo. Como señala Rowe (1998): Afrodita no anda sin el Amor (180d) porque no hay sexo sin deseo. El acto sexual fuertemente corpóreo, la esfera de la sensualidad y los placeres físicos son denominados tà aphrodísia. Pero como bien indica Rowe, no hay sexo sin deseo sexual. Y a Platón le interesa particularmente el deseo, esto es, el amor (éros) que, aunque se revelare ya más profundo que el mero acto físico, sin embargo surge con él.

Finalmente, lo que resulta interesante del planteo de Pausanias es que, en la distinción de dos Amores, el Amor puramente corporal también resulta divino y, aunque menos digno que el Celestial, también debe ser alabado; y que el Amor Celestial, al verse también acompañado de una Afrodita, se ve asimismo necesariamente mezclado con el cuerpo. En general se interpreta que la pederastia que propone Pausanias habilita la concesión de favores sexuales como parte de la relación maestro-discípulo porque así el amante-maestro obtiene una recompensa por educar al joven bello. Pero lo que debemos preguntarnos siempre es, ¿cuál es la intención de Platón tras estos juegos de pretensiones dramáticas? En cierta medida, Platón nos enseña - al jugar siempre a las escondidas - a despertar la curiosidad atenta y perspicaz de la filosofía. Y bien, ¿qué podemos encontrar detrás de la pederastia celeste de Pausanias?

En este elogio leemos que aquellos inspirados por el Amor Vulgar, hijo de padre y madre, se acercarán tanto a los hombres como a las mujeres, preocupándose únicamente por un placer superficial y momentáneo: el acercamiento caprichoso de los cuerpos. Por otro lado, los que sigan al Amor hijo del Cielo, se acercarán solamente a los muchachos y amarán sus almas estables y etéreas. De esta forma se distingue claramente el cuerpo del alma. Así, leemos:

Las personas de este tipo [el del Amor Vulgar] aman, en primer lugar, no menos a las mujeres que a los muchachos. A su vez, aman sus cuerpos más que sus almas, y además aman en lo posible a los más idiotas, en vistas solamente de lograr su cometido, sin preocuparse de lo que está bien o no. [...] Por el contrario, el que deriva de la Afrodita Celestial, en primer lugar, no participa de mujer sino solo de hombre, y este es precisamente el amor de los muchachos. (181a-c)

Con esto, el cuerpo aparenta haber quedado devaluado en el polo vulgar de los asuntos eróticos, y entonces pareciera ser necesario rechazarlo para encaminarse a la virtud de la mano del Amor Celestial, única vía digna del hombre digno. ¿Pero acaso los muchachos no se ven atraídos entre sí también por sus cuerpos? ¿No se complacen físicamente? ¿No se aman también por su belleza visible? Una lectura más detallada del discurso de Pausanias nos mostrará que los Amores Vulgar y Celestial no separan en dos polos intocables al cuerpo y al alma. Más bien, en el primer caso predomina la intervención del cuerpo mientras que en el segundo este es colocado en un rango de importancia menor al de los asuntos del alma, pero nunca es eliminado por completo. Lo que es importante, señala Pausanias, es cómo amamos, de manera que podamos amar bella y no vulgarmente. Así, en su elogio, hallamos lo siguiente:

En verdad, toda actividad es así: hecha por ella misma no es ni linda ni fea, como lo que estamos haciendo nosotros ahora, o beber o cantar o charlar. No hay nada de 
esto en sí mismo bello, y sin embargo en la práctica resulta así, porque si se actúa bien y adecuadamente resulta bello, pero si no se actúa adecuadamente, resulta feo. De hecho, así sucede también con el amar, y no todo Amor es bello ni digno de ser elogiado, sino el que nos exhorta a amar bien. (180e-181a)

Este pasaje resulta clave para no confundir el mensaje del discurso de Pausanias con un llano dualismo que separa tajantemente el Amor Celestial del Vulgar. La pederastia celeste que Pausanias pretende establecer concede la complacencia a los amantes, siempre y cuando se la realice con orden y en el marco de las reglas (182a). Para dar cuenta de esto, Pausanias hace una especie de relevamiento sociológico con el que muestra qué tan insólitas son las leyes de otras ciudades con respecto al amor, y en cambio qué justa es la ley ateniense, que celebra el afecto entre los amantes. Ocurre que, mientras que en otras ciudades complacer a los amantes no tiene ninguna restricción ni reparo, en Atenas la ley indica amar abiertamente y amar más la belleza intelectual que la belleza física, y así - únicamente así- en tanto se ame bella y correctamente, es decir, dejando al cuerpo en un segundo plano, no será para nada vergonzoso complacer a los amantes ni que los amantes adopten una especie de esclavitud amorosa para con sus amados, atendiendo a todos sus pedidos y reclamos:

Por cierto, cuando amante y amado apuntan a lo mismo, ateniéndose ambos a la ley, uno sirviendo al amado que lo complace en aquello que sea posible servirlo con justicia, y el otro ayudando a quien lo hace sabio y bueno [...], entonces, precisamente, cuando se reúnen ambos en lo que es igual en ambas legalidades, solo en ese caso sucede que es bello que el amado complazca al amante, pero en ninguna otra circunstancia. (184d-e)

Amar bellamente es entonces amar más al alma que al cuerpo, más lo estable que lo inestable, más el carácter virtuoso que los dotes físicos y materiales. Aquellos que amen según el Amor Vulgar, explica Pausanias, amarán más sus cuerpos que sus almas (181b), es decir, sus deseos sexuales y físicos serán preponderantes por sobre cualquier rasgo intelectual o espiritual. Las acciones de estos amantes son consideradas vergonzosas porque estos atienden únicamente a aquello que es inestable y pronto se marchita y desaparece. En cambio, al dirigir el ardor amoroso al carácter virtuoso y espíritu estable del otro por sobre su cuerpo, el amante habrá optado por un camino digno de alabanza.

Así, en este punto la pederastia converge con la filosofía: cuando amante y amado son guiados por el Amor
Celestial, su relación primordialmente espiritual apunta de ambos lados por igual al cuidado de sí, desembocando con sensatez y justicia en la virtud. Solo así es bello que el amado complazca al amante. De manera tal que amar el cuerpo no es vergonzoso en sí mismo, siempre y cuando el acercamiento físico y la atracción por la belleza corporal esté claramente determinada en un segundo plano y se atienda primariamente al cuidado de uno mismo a un nivel espiritual, alimentando el alma de conocimientos y encaminándose así a la virtud.

\section{Erixímaco}

Para Erixímaco, su compañero Pausanias hizo bien al presentar un Amor doble pero no profundizó este punto en su totalidad. El Amor, según el médico Erixímaco, se extiende sobre las almas y los cuerpos, pero no solo los cuerpos de los seres humanos sino también sobre el resto de los seres vivos y, en general, sobre todo lo existente. Desde la medicina, Erixímaco considera en particular el amor de los cuerpos y se refiere - dentro de la naturaleza corpórea - a un Amor de lo sano y otro de lo enfermo (186b). Entonces, la dualidad que se había establecido en el discurso anterior entre el cuerpo y el alma del ser humano se profundiza ahora en el nivel de lo físico. Erixímaco recupera la idea de Pausanias acerca de la bondad y belleza en complacer a los hombres buenos, pero ahora en lo que refiere a los cuerpos, donde es bello complacer los aspectos buenos y sanos de cada uno:

También en los cuerpos mismos, es bello y se debe complacer a los aspectos buenos y sanos de cada cuerpo, y eso es lo que lleva el nombre de «medicinal», mientras que es vergonzoso complacer a los malos y enfermos y se los debe tratar con desprecio. (186c)

Es interesante observar cómo en este discurso a partir de una profundización del esquema dual de Pausanias, se incluye al cuerpo sin por ello aceptarlo licenciosamente en todos sus aspectos. Gomes de Pina (2012) lo pone en estos términos: el discurso de Erixímaco introduce no solo un criterio para controlar un exceso sino también para atender al bienestar físico. El Amor que con Fedro carecía de padres y con Pausanias consiguió, en su duplicación, padre por un lado, y madre y padre por el otro, en el caso de Erixímaco estará acompañado por musas: Celeste en el caso del Amor bello, Polimnia en el caso del vulgar o enfermo. Este último, ahora al interior del cuerpo, no es rechazado pero requiere que se lo considere con cautela: así por ejemplo la medicina debe arbitrar 
bien los deseos relativos a la técnica gastronómica, para que haya placer sin enfermedad. De la misma forma en el banquete decidieron no negarse por completo la bebida, pero sí beber moderadamente para que resultara agradable en la medida de lo saludable. El cuerpo debe ser atendido por el buen médico, de cuyo campo de especialización Erixímaco asegura que el Amor es gobernante, pues la medicina es el conocimiento de los amores del cuerpo tanto en su estado sano como enfermo.

Debemos recordar la relevancia de la técnica médica en la construcción del cuerpo como objeto conceptual en la antigua Grecia. Platón elige audazmente a un médico entre los invitados del banquete, y con esto propone al Amor como gobernante del cuerpo, trayendo a la medicina a su propio juego filosófico. Erixímaco revaloriza al cuerpo entero desde una concepción del universo físico que el Amor abraza con todo su poder. Así, con su elogio, el médico introduce un elemento clave $-\mathrm{el}$ del bienestar físico - con el que Platón se ocupa de darle un lugar de cuidado y atención al cuerpo.

En general se entiende que la tarea medicinal se vuelca enteramente al cuerpo, mientras que la filosófica se encarga del alma. Esta es la lectura de Gomes de Pina (2012), de quien leemos: "Si la tarea del médico es promover el equilibrio del cuerpo, la tarea del filósofo será promover principalmente el equilibrio del alma, siempre en lo que respecta al fenómeno erótico" (p. 191). La autora llama por esto a la técnica de Erixímaco "medicina filosófica”. Pareciera que la opinión de Gomes de Pina funciona por analogía: Erixímaco enseña un cuidado y un concepto de modificación en el cuerpo para pasar de la enfermedad a la salud que el filósofo aplicará luego a lo que verdaderamente le importa, a saber, el alma, para pasar de la ignorancia al conocimiento. Lo filosófico de la medicina en tal caso no estaría más que en la forma de actuar pero no en el contenido. Sin embargo, según Erixímaco, el poder del Amor se extiende no solo sobre los cuerpos de los humanos sino también sobre sus almas, y aún más allá, sobre todo lo existente, incluso lo divino. Por lo cual, en primer lugar, no podemos dejar de considerar que Erixímaco no se ciñe a su propia técnica, y no olvida que es al Amor, y no a ella, a quien está elogiando. Pero además, aclara que, si bien existen dos Amores, tal y como había señalado Pausanias, ambos deben ser preservados. Si en el discurso anterior mostramos ciertos indicios para justificar que el cuerpo no es totalmente rechazado porque tiene incidencia también en el Amor Celestial, en este la dualidad es expresamente abrazada: "Tanto en la música como en la medicina y en todas las demás cosas, tanto las humanas como las divinas, hay que preservar, en tanto sea posible, cada Amor, pues ambos están presentes" (187e). Erixímaco insta a conservar tanto el Amor Celeste como el Amor de Polimnia. Así, en lo que refiere al cuerpo, no se busca un total rechazo de la enfermedad sino una armonía y una concordia entre los aspectos disímiles. En consecuencia, si Platón incluye a este médico en su diálogo filosófico, entonces deberíamos cuestionarnos si la filosofía se encarga solamente de promover el equilibrio del alma o más bien está considerando un modelo antropológico en el cual el cuerpo se hace indudablemente presente. Si es así, sería imprudente de parte de la filosofía hacerlo a un lado.

Según explica Erixímaco, el Amor hace que se produzca una armonía entre los estados disímiles del cuerpo: un cuerpo ordenado amorosamente sabrá arbitrar bien los deseos para que haya placer sin enfermedad, y se disfrute de la salud en los marcos de la mesura armónica. Si bien aparece aquí un desprecio al aspecto enfermo del cuerpo, una vez más esta actitud no implica un desprecio total en sentido de rechazo o desconsideración, pues en tal caso jamás podría darse la armonía que la medicina infunde con amor. Así como el buen músico utiliza lo grave y lo agudo para hacer una sinfonía con los elementos disímiles presentes, así también el buen médico es aquel que "a las cosas más enemigas en el cuerpo pueda hacerlas amigas y que se amen mutuamente" (186d). Lo sano y lo enfermo en el cuerpo, diferentes, se aman y desean entre sí, como todo lo disímil ama y desea lo disímil (186b). Como apunta Ludueña (2015), el médico no prescribe la abolición del amor malo, y en cambio pretende usarlo según sabia medida para evitar sus efectos indeseables sin dejar de disfrutar de sus placeres. Con lo cual no todos los deseos del cuerpo son considerados detestables, y de hecho todos son necesarios para lograr una armonía. Así es como el Amor actúa también abrazando las diferencias cuando opera con armonía en las estaciones del año, al mezclar con cautela lo frío y lo caliente, y lo húmedo y lo seco, trayendo prosperidad y salud a los hombres y los demás animales, mientras que si actúa con exceso destruye muchas cosas y comete graves daños. Platón enseña a través de Erixímaco a tratar al cuerpo con amor. ¿Para qué habría incluido Platón a un médico con estas características en su banquete, si su filosofía se tratara únicamente de despreciar al cuerpo y atender al alma solamente? A partir de la medicina de Erixímaco, las partes diferentes del cuerpo - de cualquier cuerpo- se aman mutuamente organizándose de 
manera armónica para que sus acciones resulten mesuradas. ¿Podrá ser que en el ser humano, o incluso en un orden universal, las partes diferentes también se amen mutuamente y lo corpóreo se armonice con lo incorpóreo, el cuerpo se enamore del alma y el alma del cuerpo, para alcanzar la felicidad?

\section{Aristófanes}

Aristófanes nos sumerge en un relato profundamente corporal en el que la búsqueda de la felicidad del ser humano es relatada como la búsqueda de la otra mitad del cuerpo de cada individuo. Después de que Zeus divide los perfectos cuerpos humanos, las mitades carentes andan en una constante búsqueda de su otra parte, anhelando el reencuentro con su propio fragmento. Así, leemos: "Cada uno de nosotros es un fragmento (sýmbolon) de hombre, porque está cortado como los rodaballos, hecho dos de uno. En efecto, siempre busca cada uno su propio fragmento (191d)". En este discurso, Platón caracteriza al ser humano mutilado como un sýmbolon. El sýmbolon griego era un objeto cortado en dos cuyas partes una persona y otra conservaban para comprobar luego, al encastrar los pedazos reconstruyendo la unidad, las relaciones de hospedaje. Así, estos objetos funcionaban a modo de reconocimiento. De allí que el término sýmbolon (del sustantivo symbolé, encuentro, reunión) pase a significar "marca”, "señal”, "signo", "contraseña", "símbolo". El otro como sýmbolon en este sentido es la seña secreta que abre las puertas al mutuo conocimiento.

El corte en fragmentos simbólicos a partir de una naturaleza originaria única permite al relato aristofánico, por un lado, retomar la distinción entre lo femenino y lo masculino, otorgando un lugar a cada combinación posible: si el ser humano primigenio era de una naturaleza andrógina, la unión que busquen los fragmentos será entre un hombre y una mujer, con lo cual vivirá la especie: con esto Aristófanes señala la importancia de la procreación de los cuerpos entre lo masculino y lo femenino (191c). Pero, como también existía un género puramente femenino y otro masculino, cuando estos seres fueron mutilados, se producía la unión homoerótica tanto entre dos varones como entre dos mujeres (191d-192a). En todos estos casos el cuerpo, lejos de ser despreciado, resulta necesario para provocar la unión con otros cuerpos en una búsqueda guiada por el Amor. Será este último quien devuelva al ser humano su antigua naturaleza, allí donde los cuerpos eran uno, masculino, femenino o andrógino. Por otro lado, la satisfacción física no es para nada descripta como vulgar o despreciable, sino que aparece en todos los casos de manera positiva, porque si no produce la continuidad de la especie, al menos resulta un consuelo para aquellos que no encuentran todavía lo que les es propio. Leemos:

Como Zeus se apiadó, recurrió a otro artilugio y les pasó sus zonas genitales hacia adelante, porque hasta entonces las tenían por fuera [...], y por medio de ellas creó la generación de unos en otros, por medio de lo masculino en lo femenino, para que por eso, en el momento mismo de la unión, si se encontraba un hombre con una mujer, engendrara y viviera la especie, mientras que si en ese momento se encontraba varón con varón, surgiera al menos la satisfacción del contacto, descansaran, se orientaran al trabajo y se preocuparan del resto de la vida. (191c-d)

Si bien esto ha llevado a algunos intérpretes a creer que el discurso de Aristófanes tiene como fin justificar las pasiones que apegan al ser humano al deseo sexual, en mi caso considero que en el discurso de Aristófanes (como hemos analizado en los encomios anteriores), aunque el cuerpo es un claro protagonista, el fin del elogio no se encierra en el ámbito físico. El cuerpo en el discurso del poeta funciona, en tanto símbolo, como incentivo para una búsqueda más profunda. Esta hipótesis se manifiesta con mayor claridad en lo que sigue. Los cuerpos cortados a la mitad andan siempre en busca de su otra parte, pues su mera existencia corrompida los lleva, de la mano del Amor, a reencontrarse con su propio fragmento. Sin embargo, hay algo particular en el propio cuerpo de cada ser mutilado que es señal de otra cosa, que va más allá de sí mismo, como un sýmbolon. Cuando los humanos mutilados ven sus propios cuerpos, hallan en sí mismos una marca que les recuerda su antigua naturaleza de completitud. Zeus, al mandar a cortar a los individuos, pedía también a Apolo que les girara las caras y la mitad del cuello hacia el corte, y les alise la piel sobrante:

Además alisó las numerosas otras arrugas y modeló los pechos con un instrumento, como los zapateros que alisan las arrugas de los zapatos en la horma, y dejó pocas, las que están alrededor del abdomen mismo y del ombligo, para que sea un recuerdo (mnemeion) del antiguo estado. (191a)

En este pasaje se puede observar la minuciosidad con que Platón se refiere al cuerpo a través de Aristófanes, y sobre todo, cómo se vuelve manifiesto que es el cuer- 
po, en sus arrugas y su ombligo, el que funciona como recordatorio de un estado ahora desaparecido. No podemos dejar de ver que es el mismo cuerpo expresión de una falta, y en este sentido surge con él la posibilidad de una intervención positiva en su uso. El relato de Aristófanes plantea la posibilidad de usar el cuerpo para recordar un conocimiento que antiguamente se poseía $y$, entonces, la mitad simbólica, tras la consciencia de la falta, se plenifica de deseo $^{8}$ y enciende la búsqueda de su otra mitad para curar la humanidad con el feliz encuentro. Aristófanes se refiere al Amor como una guía que traerá una "cura", como si la humanidad mutilada estuviera enferma, probablemente inspirado por el anterior orador que fue Erixímaco, un médico. Inspirada yo también por estas ideas, propongo pensar al cuerpo del relato del comediógrafo como un sintoma, recogiendo con esto a la vez las ideas de "símbolo" y "recuerdo". El cuerpo en tanto que síntoma muestra y vuelve evidente el presente malestar del ser humano. Los pedazos incompletos, las arrugas y el ombligo sacan a la luz un estado enfermo, y su contracara, un estado original perfecto, o digamos "saludable", que de otra forma sería invisible. Incluso, el "cuerpo síntoma” reafirma y realza la noción del "cuerpo sýmbolon" todavía antes del encuentro con el otro, pues es de hecho la consciencia de la falta que las marcas del cuerpo mutilado revelan como un síntoma la que incentiva la búsqueda que llevará a ese reencuentro simbólico con el otro fragmento original. Pero incluso cuando las mitades perfectas se encuentran, ambos se dan cuenta que no es el placer de los cuerpos lo que quieren, y que la juntura de sus ombligos y genitales no basta, con lo cual se problematiza en un tono más profundo la pretensión amorosa.

El cuerpo, en sus pedazos incompletos, sus arrugas y su ombligo, saca a la luz un estado anterior que de otra forma sería invisible. Es únicamente la consciencia de este estado enfermo que el cuerpo síntoma brinda la que convierte al fragmento en un verdadero símbolo, encendiendo el deseo por hallar la otra mitad. Así es como el cuerpo podrá servir de incentivo para el reencuentro feliz del sano origen. Hacia el final de su elogio, el poeta sugiere:

El Amor, que en el presente nos beneficia enormemente conduciéndonos a lo propio y para el porvenir nos proporciona las mayores esperanzas, si es que nosotros le rendimos culto a los dioses, restableciendo nuestra antigua naturaleza y curándonos, nos hará bienaventurados y felices. (193d)

\section{El Banquete de Ferreri}

La película Il Banchetto di Platone de Ferreri sigue casi al pie de la letra el texto platónico, lo cual la hace un buen complemento - audiovisual - de la fuente antigua. Sin embargo, es difícil entender desde el film la posibilidad de un uso positivo del cuerpo en relación a la ética y la felicidad, y sobre todo a la filosofía, según aquí hemos intentado establecer. Quisiera detenerme ahora en aquellos lugares en los que la película se aparta del texto platónico, pues creo que es allí donde más manifiestamente puede entreverse la decisión exegética de esta particular puesta en escena. De hecho, el director ha decidido realizar ciertos agregados que proponen una interpretación que dista de la lectura que aquí presentamos. Veamos de qué se tratan estas nuevas escenas del Banquete.

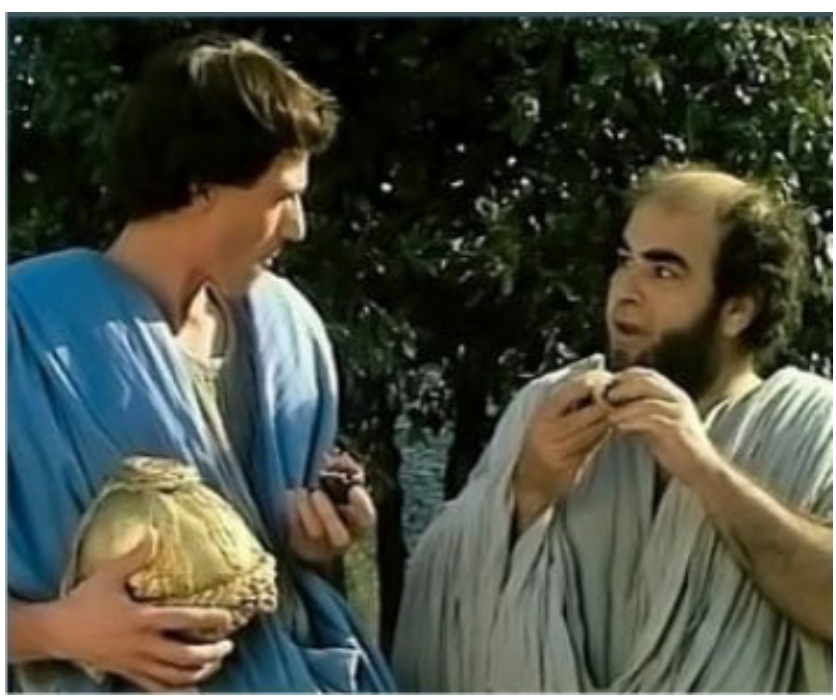

En primer lugar, mientras Fedro desarrolla su elogio, las mujeres y esclavos que están escuchando desde afuera se burlan del vínculo que el orador establece entre el Amor y la virtud: entre risas, uno de los esclavos grita ensanchando el pecho "; Yo soy el amor!". Más adelante, cuando termina de hablar Pausanias, entran varias mujeres divertidas que intentan seducir a los hombres, y Agatón las echa excusándose con que aquella noche estaban haciendo "algo importante". Ninguno de estos acontecimientos aparecen en el texto de Platón, y ambos subrayan el hecho de que los discursos teóricos tenían un carácter de seriedad diferente a la atmósfera más festiva de los banquetes regulares que terminaban en borracheras y orgías. De igual modo vemos representada la manera en que las mujeres y los esclavos tenían de entender el amor (i. e. en su carácter puramente sexual). Si bien estas notas podrían en principio convivir con la lectura que 
aquí presentamos, la decisión de realizar estos agregados a la dinámica del banquete fortalece la idea de que la sexualidad está desligada, o incluso es opuesta a la ética. En particular el personaje de Aristófanes está representado en el film desde un lugar primordialmente cómico e incluso ridículo. (Recordemos que esta también es la lectura tradicional de este personaje, como las que hacen Nussbaum o Rowe). En el film hallamos que mientras Erixímaco está terminando su discurso, Aristófanes que ya se había quejado con Agatón al echar a las mujeres - abandona el salón para ir a sentarse junto a algunas mujeres que estaban afuera, a quienes comienza a seducir y halagar (otro agregado ajeno al texto platónico). Es Sócrates quien tiene que llamarlo a los gritos para que regrese cuando llega su turno. Además, en la película Aristófanes utiliza los cuerpos de los presentes para graficar su relato: con sus brazos se engancha de espaldas a otro hombre, a quien levanta del suelo para mostrar cómo se movían los seres humanos originalmente, lo cual el resto encuentra chistoso. Con todo esto, si bien el discurso del poeta recibe comentarios positivos de algunos de los presentes, resulta difícil tomar su relato con la profundidad con que aquí hemos pretendido mostrarlo.

Finalmente, parece que la película, siguiendo la línea de interpretación más clásica del Banquete, pretende preparar a los espectadores para el discurso del filósofo, como si este fuera el único que tiene algo verdadero para decir con respecto al Amor. Cuando Sócrates termina su elogio, pues, cuenta Apolodoro que "todos aplandieron" ya que habían quedado muy sorprendidos con sus palabras, según las cuales "el momento de contemplación de la pura belleza no se compara en nada con” los bellos cuerpos de los jóvenes que hoy los vuelven locos". Esta jerarquía establecida para con el discurso del filósofo (manifestada por los aplausos unánimes) es otro agregado de Ferreri que desliga la pura belleza de los bellos cuerpos. Y el punto es que, una vez más, la decisión escénica de la película se aleja del texto platónico. En el texto fuente leemos que Sócrates, cuando termina su discurso, "es elogiado" (Smp. 212c), pero no que todos lo aplanden, como relata Apolodoro en el film. De hecho, en el texto los elogios son rápidamente desvanecidos cuando Aristófanes pretende decir algo e irrumpen los gritos de Alcibíades que llega con sus amigos: "Después de que Sócrates dijo esto, algunos lo alabaron, mientras que Aristófanes trataba de decir algo, porque Sócrates al hablar habia aludido a su discurso. Abí, de golpe, la puerta del patio bizo un tremendo ruido..." (Smp. 212c). En el texto platónico, es en cambio Agatón quien al finalizar su elogio es aplaudido no por algunos sino por "todos los presentes" quienes "lo aclamaron con gran algarabia” (Smp. 198a). En definitiva, observamos que la película reproduce en gran medida las interpretaciones más tradicionales del Banquete, según las cuales el cuerpo queda devaluado a la esfera más oscura de lo puramente sexual desligado del carácter filosófico. Encontramos esta lectura en los agregados que Ferreri decide hacer a la literalidad del texto platónico.

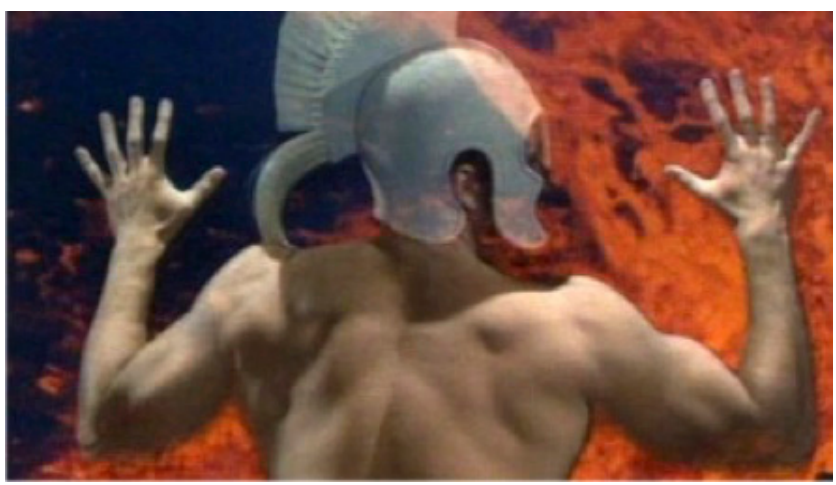

No obstante, creemos que a la luz de este contrapunto que establecimos entre la lectura de Ferreri y la nuestra, la película resulta positivamente una oportunidad de reflexión acerca del rol que puede tener el cuerpo en la acción filosófica. Lo corporal, de hecho, se impone como un claro protagonista en la película de Ferreri. La corporalidad está latente en los primeros discursos, por ejemplo, ilustrada por algunas imágenes que aparecen en pantalla a medida que los personajes desarrollan sus elogios: vemos fotogramas de volcanes en erupción, pájaros en vuelo y cuerpos humanos desnudos que se intercalan con las palabras de encomio. En particular en el discurso de Aristófanes aparecen imágenes de cuerpos de niños tocándose el ombligo y mirando sus reflejos en un espejo, y también una mujer embarazada, ambos símbolos del encuentro con la otra mitad y la procreación descriptos en el relato del poeta. También tenemos, a lo largo de toda la película, la posibilidad de ver a Glaucón y Apolodoro recorriendo la ciudad mientras el último narra lo sucedido en aquel banquete en la casa de Agatón ${ }^{10}$. Y allí también se dan espacios de cotidianeidad que se intercalan en los discursos teóricos del banquete: Glaucón y Apolodoro caminan, van al mercado, comen, se encuentran con unas mujeres, se sientan en el campo bajo el sol, mientras cuentan y se entusiasman acerca de los elogios del amor. Muchas veces se ha comparado el cine con aquel lugar descripto en la alegoría de la caverna en la República de Platón, diálogo donde el filósofo pone en tela de juicio el rol de la poesía en la polis. ¿Cuál es, pues, el sentido de verdad que podemos encontrar en el discurso dramáti- 
co y artístico del cine? Creemos, como sostiene también Soares (2013), que Platón no propone una desvinculación sino más bien una subordinación de la poesía a la filosofía. Si ponemos el film al servicio de nuestra mirada filosófica, entonces podremos seguir reflexionando críticamente: ¿es el deseo sexual un impulso totalmente desligado y opuesto al deseo por el conocimiento? ¿Es el cuerpo un impedimento para dedicarse a la búsqueda filosófica? ¿Podemos utilizar el cuerpo y sus deseos y la sexualidad para encaminarnos en la vía del amor a la sabiduría?

\section{Conclusión}

Tras estas miradas poliédricas al interior del Banquete, podemos concluir que desde el comienzo del diálogo Platón elabora una noción de cuerpo cargada de sentido, a partir de la cual se van estableciendo varios indicios para pensar una visión positiva de la esfera de la corporalidad en relación a la búsqueda del conocimiento. En resumen, en el elogio de Fedro el cuerpo se presentó susceptible a la inspiración amorosa, la cual funciona como directriz para una vida virtuosa y por lo tanto feliz, a través de la vergüenza, el orgullo e incluso la muerte. En el elogio de Pausanias el cuerpo se distinguió del alma para enseñar a amar bellamente, enalteciendo el amor primordialmente espiritual por encima del amor puramente corporal o primordialmente corporal. En el tercer discurso Erixímaco incluyó al cuerpo desde una visión universal donde se armonizan amorosamente las partes diferentes. Finalmente, en el elogio de Aristófanes el cuerpo apareció como un símbolo y un síntoma que incentiva la búsqueda amorosa del origen y la felicidad. En estos cuatro discursos Platón va elaborando un modelo antropológico en el cual el rol del cuerpo se hace indudablemente presente para la búsqueda amorosa de la sabiduría, esto es, la filosofía, al tiempo que se entretejen vínculos estrechos con la ética y la felicidad. En el film de Ferreri analizamos un caso exegético que presenta al cuerpo desde un lugar distinto al de nuestra lectura, al realizar ciertos agregados que ligan a lo corporal a un ámbito puramente sensible que no logra alcanzar el conocimiento. Con esta decisión, el Banquete de Ferreri reproduciría las interpretaciones más clásicas del texto platónico con las que aquí discutimos. No obstante, rescatamos que la película sigue bastante al pie de la letra el diálogo platónico, y en su puesta en escena el cuerpo se impone como un claro protagonista. Desde aquí, hemos establecido la posibilidad de poner al cine al servicio de la filosofía para seguir repensando el rol del cuerpo en la búsqueda del conocimiento. En la temática particular de este estudio, resulta clave la posibilidad de hacernos de un recurso audiovisual para repensar el cuerpo, porque es justamente la película la que, a través de su puesta en escena, le otorga un cuerpo al banquete, mostrándonos los cuerpos de los personajes en movimiento, con sus acciones y reacciones, sus miradas e incluso sus sentidos más metafóricos, a través de imágenes de cuerpos jóvenes, embarazados, cuerpos animales, cuerpos reflejados en espejos y volcanes en erupción, símbolo ardiente del amor que se enciende.

\section{Referencias}

Boeri, M.D. (2016). Éros y synousía en el Simposio, en M. Tulli \& M. Erler (Eds.), Plato in Symposium. Selected Papers from the Tenth Symposium Platonicum (pp. 362-370). Akademia Verlag.

Broadie, S. (2001). Soul and Body in Plato and Descartes en Proceedings of the Aristotelian Society. New Series, 101, $295-308$.

Bury, R. G. (1932). The Symposium of Plato, with Introduction, critical Notes and Commentary. Heffer \& Son.

Casertano, G. (1997). Il (in) nome di Eros. Una lettura del discorso di Diotima nel Simposio platonico. Elenchos, XVIII, 277-310.

Chen, L. C. H. (1983). Knowledge of Beauty in Plato's Symposium. New Series, 33(1), 66-74. Cambridge University Press.

Cornford, F. M. (1974). La doctrina del éros en el Banquete de Platón (1974), en La filosofía no escrita. Editorial Ariel.

Dover, K. (1980). Plato. Symposium, edition with introduction and commentary. Cambridge.

Ferreri, M. (director). (1988). Banchetto di Platone [película]. FR3, La Sept, FIT Production, Gruppo Bema.

Fierro, M. A. (2019). Amor carnal, amor platónico en el Banquete. Estud.filos, (59), 189-219.

Fierro, M. A. (2001). Narrar el verdadero amor. El sentido de la estructura narrativa en el Banquete de Platón, en V. Juliá (ed.), Los antiguos griegos y su lengua (pp. 23-38). Biblos.

Ludueña, E. (2015). Platón, Banquete. Traducción, introducción y notas. Colihue. Mársico, C. (2009). Platón, Banquete. Miluno.

Peixoto, M.C.D. (2012). Corpo, anima, visibile, invisibile nel Simposio platonico, en Jr. Borges de Araujo y G. Cornelli, Il Simposio di Platone: un banchetto di interpretazioni (pp. 159-179). Lofredo Editore. 
Reale, G. (2010). La concepción del hombre, en G. Reale y D. Antiseri, Historia del Pensamiento Filosófico y Científico. Tomo I. Antigüedad y Edad Media. Herder.

Rowe, C.J. (1998). Plato. Symposium, edited with an Introduction, Translation and Commentary. Aris \& Phillips Classical Texts.

Soares, L. (2013). La significación ética de la mímesis poética en la República de Platón y su influencia en la estética de Gadamer y Badiou. Cuadernos de Filosofía, 60, 27-41.

Vernant, J.P. (2001). El individuo, la muerte y el amor en la Antigua Grecia. Paidós.

1 Entre estas lecturas podemos destacar las de Fierro (2019), Broadie (2001) y Casertano (1997)

2 En esta línea se inscriben los trabajos de Dover (1980), Reale (2010), Boeri (2016), Vernant (2001), entre otros.

3 Todas las citas de fuente platónica son del Banquete y se verán citadas directamente con las referencias de los pasajes según la paginación de Stephanus

$4 \quad$ En esta línea hallamos también la lectura de Chen (1983)

5 Si bien el discurso de Agatón podría entrar en esta primera dinámica competitiva, el abordaje que aquí he elegido lo dejaría quizás mejor en un segundo giro caleidoscópico: el elogio de Agatón sirve pues, para que Sócrates lo refute mostrándole que se encuentra en la misma situación de ignorancia en la que él mismo se encontraba antes de que Diotima lo inicie en los asuntos amorosos. El tercer giro lo dará la inesperada aparición de Alcibíades y el resto de sus amigos que llegan generando un gran alboroto.

$6 \quad$ En Smp. 175d Sócrates y Agatón discuten brevemente acerca de la posible transferencia del saber, y el filósofo opina que sería bueno si la sabiduría pudiera fluir con el contacto «como el agua en las copas que fluye a través de una hebra de lana de la más llena a la más vacía».

7 De manera similar estas interpretaciones aparecen en el discurso de Fedro y Pausanias, como hemos planteado. Para el caso de Aristófanes vid. Rowe, 1998, p. 153.

8 Recordemos que en el discurso de Sócrates, el deseo (éros) será caracterizado en relación con la noción de carencia, como deseo de algo que falta, y nunca de algo que ya se posee (200a). Esta idea de carencia vinculada al deseo aparece ya en el discurso de Aristófanes a partir de la falta explícita de la otra mitad del cuerpo.

$9 \quad$ En este aspecto, Rowe (1998: 202) destaca cómo la recepción del discurso de Sócrates «contrasta con la ruidosa recepción dada al discurso de Agatón». Igualmente Bury (1932) señala que Sócrates no es aplaudido con el mismo entusiasmo que Agatón (p. 134)

10 Véase Fierro (2001) acerca de la estructura narrativa del Banquete. 